\title{
Passagem de plantão: falando de paradigmas e estratégias
}

\author{
Shift report: talking about paradigms and strategies \\ Pasaje del turno: hablando de los paradigmas y las estratégias
}

Ivana Lucia Correa Pimentel de Siqueira' ${ }^{1}$, Paulina Kurcgant ${ }^{2}$

\begin{abstract}
RESUMO
O objetivo deste artigo é apresentar quatro modalidades de passagens de plantão, implementadas em unidades de internação de um hospital privado de São Paulo, destacando os pontos negativos e positivos. A discussão destes pontos baseou-se no resgate de informações da literatura pertinente na experiência vivencial das autoras. Os diferentes tipos de passagem de plantão foram implantadoas conforme a estratégia adotada, sequencialmente, visando minimizar problemas de horas extras, devido à duração da passagem de plantão e às diferenças na compreensão das informações. As duas últimas estratégias pertencem a um conjunto de ações propostas em um modelo de gestão implantado no referido campo. Destaca a necessidade de integração entre a estratégia utilizada na passagem de plantão e o modelo assistencial vigente, o tipo de escala de divisão de serviços e a qualidade das anotações do prontuário. Ressalta que o compromisso e a capacitação dos profissionais são fundamentais na obtenção de resultados.
\end{abstract}

Descritores: Comunicação não verbal; Cuidados de enfermagem; Equipe de enfermagem; Supervisão de enfermagem

\begin{abstract}
The goal of this article is to present four models of shift report, which had been implemented over the years on inpatient medical-surgical units in a private hospital in São Paulo City, Brazil. The article highlights the negative and positive points or each model. The discussion of these points is based on information from literature and the clinical experience of the authors. Strategies adopted by each model are also discussed such as the ways to minimize overtime, duration of shift report, and differences in understanding the information. The strategies point out the necessity of integration between the shift report and the existing model, the type of shift and the distribution of services, and the quality of the handbook notes. Whichever model of shift report is adopted, the commitment and qualification of the professionals are fundamental for the achievement of positive results.
\end{abstract}

Keywords: Nonverbal communication; Nursing care; Nursing, team; Nursing, supervisory

\section{RESUMEN}

El objetivo de este artículo es presentar cuatro modalidades de entrega de turno, implementadas en unidades de internamiento de un hospital privado de São Paulo, destacando los puntos negativos y positivos. La discusión de estos puntos se basó en el rescate de informaciones de la literatura pertinente y en la experiencia vivida por las autoras. Los diferentes tipos de entrega de turno fueron implantados de acuerdo a la estrategia adoptada, secuencialmente, con vistas a minimizar problemas de horas extras, debido a la duración de la entrega de turno y a las diferencias en la comprensión de las informaciones. Las dos últimas estrategias pertenecen a un conjunto de acciones propuestas en un modelo de gestión implantado en el referido campo. Se destaca la necesidad de integración entre la estrategia utilizada en la entrega de turno y el modelo asistencial vigente, el tipo de escala de división de servicios y la calidad de las anotaciones de la historia clínica. Se resalta que el compromiso y la capacitación de los profesionales son fundamentales en la obtención de resultados.

Descriptores: Entrega de turno; Información; Administración en Enfermería

\footnotetext{
1 Doutoranda da Escola de Enfermagem da Universidade de São Paulo - USP - São Paulo(SP), Brasil.

2 Professora Titular do Departamento de Orientação Profissional da Escola de Enfermagem da Universidade de São Paulo - USP - São Paulo(SP), Brasil.
} 


\section{INTRODUÇÃO}

A passagem de plantão é um mecanismo utilizado pela Enfermagem para assegurar a continuidade da assistência prestada ${ }^{(1)}$. Este evento, constitui uma atividade fundamental para a organização do trabalho ${ }^{(2)}$.

Na passagem de plantão acontece a transmissão de informações entre os profissionais que, terminam e os que iniciam o período de trabalho. Abordam sobre o estado dos pacientes, tratamentos, assistência prestada, intercorrências, pendências e situações referentes a fatos específicos da unidade de internação que merecem atenção.

Neste processo pode-se adotar várias formas de comunicação, entretanto, as formas verbal e escrita são as mais comuns, destacando-se a verbal.

Autores ${ }^{(3-4)}$ esclarecem que a comunicação verbal refere-se à linguagem falada e sofre influências da cultura e dos costumes das pessoas, implicando em diferenças na apresentação e compreensão. Ainda, neste tipo de comunicação estão implícitas as formas não verbal e paraverbal, as quais também influenciam na interpretação dos receptores.

Sawada e Galvão( ${ }^{(5)}$ definem comunicação não verbal como "uma transmissão de conteúdos, de forma transparente, onde a mensagem é emitida e recebida pelos órgãos dos sentidos, através da expressão facial, corporal, dos gestos e do toque". Complementam o pensamento referindo que a comunicação paraverbal está relacionada ao tom de voz, ritmo, suspiros, períodos de silêncio e a entonação dada, às palavras durante a conversação. Geralmente não são considerados tais aspectos no diálogo, porém estes podem confirmar ou não o que está sendo dito, desencadeando desentendimentos e possíveis problemas.

A comunicação é uma competência necessária aos profissionais de enfermagem, os quais devem estar atentos aos conteúdos informativos e resultados do processo comunicativo ${ }^{(6)}$.

Ao analisar a comunicação estabelecida nas passagens de plantão, autores vêm verificando situações anômalas.

Alguns autores ${ }^{(7)}$ evidenciaram que os elementos não verbais interferem na comunicação estabelecida nas passagens de plantão, verificando, em um estudo, divergências entre os relatos escritos e os falados, reiterando as considerações anteriores.

Pirolo ${ }^{(8)}$, avaliando o comportamento dos profissionais durante a passagem de plantão, identificou que tais eventos não constituíram uma atividade grupal, pois os indicadores de comunicação ineficazes foram predominantes em relação aos eficazes, comprometendo a recepção de mensagens.
Outro estudo realizado ${ }^{(9)}$ mostrou que ruídos e interferências atrapalham a passagem de plantão, provocando desconcentração dos profissionais, desatenção e possíveis falhas de compreensão. Verificaram que, nos horários de trocas de turnos, principalmente entre o diurno e vespertino, acontece um acúmulo de pessoas nas unidades hospitalares, dadas as visitas médicas, chegadas de pós-operatórios do Centro-Cirúrgico, dispensação de materiais e roupas, entrega de alimentos, além das visitas dos familiares. Este trânsito de profissionais e visitantes provocava o aumento dos ruídos na comunicação e solicitações aos auxiliares de enfermagem e enfermeiros, interrompendo a passagem de plantão nas unidades. Constataram, também, que estes aspectos contribuíam para aumentar o tempo utilizado nos eventos, o qual excedia 12 minutos, gerando problemas trabalhistas na instituição. As horas extras, devido ao tempo despendido nas passagens de plantão, constituíram um sério problema da Enfermagem, o que também foi abordado por Silva e Staccarini ${ }^{(10)}$.

Sendo a passagem de plantão uma atividade inerente ao cotidiano do trabalho de enfermagem e passível de problemas, como identificamos na literatura, as autoras consideram importante a divulgação de experiências e estudos sobre o tema.

Assim, o presente artigo objetiva discorrer sobre a trajetória da passagem de plantão, no referente aos paradigmas a às respectivas estratégias das modalidades implementadas nas unidades de internação de um hospital privado da cidade de São Paulo. Trata-se de quatro tipos de passagem de plantão que foram vivenciados pelas autoras, estando também apontados os pontos positivos e negativos de cada um.

Vale apontar que duas dessas modalidades fazem parte de um modelo de gestão implantado, por uma das autoras, no campo citado, o qual vêm sendo objeto de avaliação na elaboração de uma tese.

\section{APRESENTAÇÃO DAS MODALIDADES E ANÁLISE DE ESTRATÉGIAS ADOTADAS NA PASSAGEM DE PLANTÃO}

Trata-se de um relato de experiência baseado nas informações, observação e vivência das autoras no hospital em estudo da passagem de plantão nas 10 unidades de internação que contem 156 leitos clínico-cirúrgicos dos 257 leitos deste Hospital.

As estratégias foram implementadas em sequência cronológica, na tentativa de corrigir problemas emergentes, descritos a seguir, e melhorar o processo comunicativo. Alguns aspectos referentes ao modelo assistencial vigente serão apresentados para melhor análise dos dados, além da apresentação . 


\section{A PASSAGEM DE PLANTÃO POR TAREFAS}

Esta modalidade de passagem de plantão deu-se entre as décadas de 70 e 80 no referido campo. As unidades de internação adotavam a assistência dividida por tarefa, ou seja, cada auxiliar de enfermagem assumia um determinado cuidado ou um grupo deles, o qual ele realizava em todos os pacientes. Este método de prestação de serviço era comum entre os serviços hospitalares, na época, adequando-se ao reduzido contingente de pessoal.

Nesta modalidade de passagem de plantão, os auxiliares de enfermagem informavam sobre as atividades realizadas ao colega que prosseguia, no plantão seguinte, com as mesmas tarefas. Os enfermeiros comentavam a respeito do estado, assistência prestada e intercorrências de todos os pacientes, geralmente isoladamente, sem compartilhar as informações com os auxiliares de enfermagem.

Este tipo de passagem de plantão apresentava vários pontos negativos. Os enfermeiros tinham os horários de saída atrasados devido ao grande número de informações referentes aos inúmeros pacientes; a equipe não tinha conhecimento sobre a assistência integral realizada ou necessária aos pacientes, pois as informações não eram compartilhadas; os registros de enfermagem, devido ao método de trabalho vigente, apresentavam-se pouco frequentes e incompletos, dificultando o resgate de informações a serem comentadas na passagem de plantão.

Quanto aos pontos positivos, mantinha-se regularidade no horário de saída e entrada dos auxiliares de enfermagem.

Na década de 80 , aconteceu a implantação da sistematização da assistência de enfermagem nas unidades de internação, sob a forma de histórico, plano de cuidados diário e evolução de enfermagem, provocando uma revisão na metodologia assistencial ${ }^{(11)}$. Adotou-se então, a assistência por cuidados integrais, ou seja, cada auxiliar de enfermagem seria responsável pela assistência integral a um grupo de pacientes. Quanto aos enfermeiros, estes avaliariam diariamente os pacientes e seriam responsáveis pelo planejamento individualizado da assistência.

Assim, esta modalidade de passagem de plantão não contemplava a estratégia das características do novo método de prestação de assistência, nem tampouco as necessidades de informação da equipe, sinalizando a necessidade de uma nova estratégia.

\section{A PASSAGEM DE PLANTÃo EM GRUPO}

Esta modalidade foi adotada na década de 90. Constava da estratégia da passagem de plantão sob forma de reunião no posto de enfermagem, da qual participavam auxiliares de enfermagem e enfermeiros do turno que iniciava e do que terminava o período de trabalho. Os auxiliares de enfermagem faziam um relato sobre o período, pautando a assistência prestada, enquanto os enfermeiros faziam complementações.

O propósito desta reunião era informar, todos os membros da equipe, sobre os pacientes internados, mesmo sabendo-se que cada um seria responsável, apenas, por uma parcela deles. Acreditava-se que isto contribuiria para o conhecimento de todos os pacientes, melhorando a presteza nas respostas e no atendimento por qualquer membro da equipe.

Entretanto, com o passar do tempo foram verificados pontos negativos relacionados a esta estratégia. As passagens de plantão mostraram-se prolongadas, pois eram muitas as informações a serem transmitidas, devido à alta taxa de ocupação das unidades e à complexidade dos tratamentos e da assistência, propiciando relatos extensos. Surgiram problemas trabalhistas decorrentes das horas extras, bem como uma descontinuidade na prestação da assistência durante o tempo destinado à passagem de plantão, uma vez que todos os membros da equipe estavam envolvidos, ocasionando insatisfação dos clientes.

Siqueira e Muto ${ }^{(9)}$, após observarem 50 passagens de plantão pautadas nesta modalidade, no referido campo, identificaram conversas paralelas entre os profissionais, saídas aleatórias de membros da equipe para prestação de cuidados pendentes e interrupções por solicitações de outros profissionais e acompanhantes. O tempo médio de duração de cada passagem de plantão foi superior a 15 minutos.

Esta modalidade foi também, discutida por Pirolo ${ }^{(8)}$ que apontou problemas de duração, interferências e distócias na comunicação nas passagens de plantão.

Vale ressaltar que, nesta fase, a escala de prestação de serviço era alterada diariamente, ou seja, havia um rodízio diário de pacientes a serem cuidados pelos auxiliares de enfermagem. Acreditava-se que a possibilidade de conhecer diferentes patologias, tratamentos e realizar diversos procedimentos auxiliaria no desenvolvimento técnico da equipe, a despeito do prejuízo ao relacionamento entre paciente e profissional, uma vez que o curto tempo destinado ao contato não favorecia tal desenvolvimento.

Apesar do aspecto positivo advindo da idéia do compartilhamento de informações entre todos os membros da equipe, verificou-se que as informações acabavam dispersas e os pontos negativos tornavam-se mais frequentes, levando ao repensar do paradigma e a proposição de uma nova modalidade com diferente estratégia.

\section{A PASSAGEM DE PLANTÃO EM SUB-GRUPOS}

Desde 1996, um novo modelo de gestão vinha sendo implantado nas unidades de internação. Esse estava 
pautado na participação e compromisso dos profissionais e na revisão dos processos de trabalho.

Então, à luz dessas idéias, alterou-se a escala de prestação de assistência, ou seja, os pacientes seriam sempre cuidados pelos mesmos enfermeiros e auxiliares de enfermagem de cada turno até sua alta, compondo uma equipe de cuidadores entre turnos, a qual denominamos de escala fixa. As substituições ocorriam devido a folgas ou problemas de relacionamento.

Este tipo de escala de prestação de serviços possibilitou facilitar e agilizar a assistência, dado o conhecimento das individualidades dos pacientes pelos cuidadores, bem como, das respectivas patologias e tratamentos. Em consequiência, houve uma diminuição de informações a serem transmitidas na passagem de plantão, quando foi possível propor uma nova estratégia referente a essa atividade.

As reuniões foram substituídas pelas duplas de auxiliares de enfermagem, compostas por quem ingressava e por aquele que encerrava o turno, havendo uma sucinta troca de informações relevantes sobre os pacientes cuidados, salvo as situações de admissões na unidade. O enfermeiro compartilhava todas as informações, no papel de coordenador das atividades assistenciais da unidade.

Como havia dois enfermeiros por turno, foi possível organizar duas equipes de passagem de plantão, que as realizavam, simultaneamente agilizando ainda mais o processo. À medida que cada dupla encerrava, outra iniciava, imediatamente, a passagem de plantão sobre seus pacientes. Os auxiliares de enfermagem organizavam-se sequencialmente para a realização dessa atividade.

Para a realização da passagem de plantão dos subgrupos, eram utilizados dois ambientes distintos na unidade, evitando-se o posto de enfermagem, para que houvesse livre acesso às atividades referentes à medicação.

Esta modalidade segundo a estratégia dos sub-grupos foi descrita e avaliada, no referido campo, e apresentou vários pontos positivos ${ }^{(9)}$. Verificaram agilidade no processo, dado o melhor direcionamento das informações a serem transmitidas; o prontuário sedimentouse como a fonte de consultas para as respostas ou explicações a serem dadas, uma vez que cada membro da equipe informava apenas sobre alguns pacientes, o que contribuía para a coerência de informações; o atendimento durante as passagens de plantão acontecia ininterruptamente, visto que apenas dois auxiliares estariam envolvidos no evento; e, no referente às horas extras, identificaram uma média de 10 minutos além do horário regular.

Os autores acima ainda apontaram alguns ajustes propostos pelos profissionais participantes, como a construção de um resumo semi-estruturado com as informações transmitidas, o que propiciaria, aos enfermeiros, a visualização de informações e atividades prioritárias na unidade.

Quanto aos pontos negativos verificaram dificuldades na ordenação dos auxiliares para a passagem de plantão, exigindo coordenação das enfermeiras, que por sua vez estavam entretidas na complementação ou captação de informações e o fato de alguns auxiliares se ocuparem com atividades, postergando a passagem de plantão, incorrendo em atrasos.

Após dois anos de adoção desta modalidade teve início um repensar sobre o paradigma da passagem de plantão. Dúvidas sobre a necessidade deste evento eram latentes, uma vez que a passagem de plantão tratava-se, habitualmente, da transmissão das intercorrências e das pendências. Então, propôs-se um outro tipo de passagem de plantão segundo outra estratégia.

\section{ATUAL PARADIGMA DA PASSAGEM DE PLANTÃO}

Esta modalidade foi fruto do modelo de gestão que vem sendo implantado, o qual propõe a reorganização das rotinas de trabalho.

Algumas reuniões de discussão sobre passagem de plantão com profissionais da área foram realizadas. Foi então que surgiu a proposta de abolição da passagem de plantão entre equipes. Compreendeu-se que, até o término do plantão, a equipe deveria realizar a assistência planejada, transferindo a outra equipe apenas o que não conseguiu realizar. As informações resumiam-se em pendências e intercorrências, uma vez que a escala fixa, seria mantida, assegurando o conhecimento dos pacientes pelos auxiliares e enfermeiros. Ainda, foi proposto um instrumento semi estruturado denominado de Plano de Passagem de Plantão (Anexo), referente aos pacientes, com as informações importantes a serem preenchidas.

O tempo despendido, anteriormente, na passagem de plantão para troca de informações entre equipes, passou a ser utilizado para revisão das anotações sobre a assistência realizada logo ao início do plantão e antes do término. Trata-se da transferência do tempo despendido com a comunicação entre equipes para a informação da própria equipe.

$\mathrm{Na}$ descrição da operacionalização desta modalidade, o enfermeiro que inicia o plantão, reunido, individualmente, com cada auxiliar de enfermagem, tendo em mãos o prontuário e o Plano de Passagem de Plantão, faz a revisão das anotações ocorridas no plantão anterior. Nesta análise consegue priorizar as pendências, identificar os casos graves e identificar a necessidade de condutas imediatas. Já, cerca de 30 minutos antes do término, o enfermeiro, novamente, reunido com cada auxiliar, avalia os procedimentos e as anotações realizadas no turno. As ações que estão em andamento ou as que não puderam ser concretizadas são transferidas para 
o próximo turno e registradas como pendências no Plano de Passagem de Plantão, além de observações importantes sobre cada paciente.

Algumas adaptações foram realizadas no Plano de Passagem de Plantão, conforme as peculiaridades de cada unidade. Estabeleceu-se também uma pequena abordagem verbal entre os enfermeiros sobre intercorrências administrativas ou fatos merecedores de explicações.

Vale destacar que a qualificação das anotações de enfermagem foi tema de programas de capacitação das equipes, com a finalidade de melhorar os registros dos prontuários, visto que a consulta às informações neles contidas passou a ser freqüente e crucial, segundo o novo modelo.

Verificou-se ainda, pontos positivos advindos desta nova estratégia de passagem de plantão. Os enfermeiros conseguiram organizar melhor o trabalho, principalmente referente ao atendimento de prioridades; os registros passaram a ser revisados pelas equipes, diminuindo as falhas; a assistência realizada no período era avaliada pelo enfermeiro e auxiliar de enfermagem; atingiu-se o objetivo do cumprimento rigoroso de horários de entrada e saída do trabalho por toda a equipe; os enfermeiros e os auxiliares de enfermagem mostraram-se receptivos, participativos e compromissados com a assistência.

Sobre os aspectos negativos, observou-se que existia resistência dos enfermeiros na adesão imediata da nova estratégia de transmissão de informações, pois alguns consideravam imprescindível um repasse verbal de informações ao colega, o que foi sendo adaptado com o tempo.

Após um ano da adoção desta modalidade de passagem de plantão, reiteramos, esta ainda constitui em uma atividade que deve ser repensada.

\section{CONSIDERAÇÕES FINAIS}

A passagem de plantão, como uma das rotinas das instituições hospitalares, merece importante revisão e concepção de novas propostas. No estudo observou-se que a adoção de estratégias está vinculada ao método assistencial, ao tipo de escala de prestação de assistência vigente e à capacitação dos membros da equipe. Esses, por sua vez, devem ser destacados nos modelos de gestão do serviço.

As quatro modalidades de passagem de plantão apresentaram diferentes estratégias. O cumprimento fidedigno do horário de trabalho e a compreensão das informações foram aspectos relevantes a serem considerados.

A passagem de plantão mostrou-se como uma atividade que pode reavaliar o paradigma assistencial. A participação dos profissionais da equipe, a sintonia com as propostas de gestão e a avaliação contínua foram atributos fundamentais para os resultados obtidos.

\section{REFERÊNCIAS}

1. Nogueira MS. Incidentes críticos na passagem de plantão [dissertação]. Ribeirão Preto (SP): Escola de Enfermagem de Ribeirão Preto, Universidade de São Paulo; 1998.

2. Magalhães AM, Pires CS, Keretzky KB. Opinião dos enfermeiros sobre a passagem de plantão. Rev Gaúcha Enferm. 1997;18(1):43-53.

3. Bordenave JD. O que é comunicação? 14a ed. São Paulo: Paidós; 1964.

4. Weil P, Tompakov R. O corpo fala: a linguagem silenciosa da comunicação não verbal. 31a ed. Petrópolis: Vozes; 1993.

5. Sawada NO, Galvão CM. Comunicação não verbal: análise proxêmica em situações de pré-operatório. In: Anais do $3^{\circ}$ Simpósio Brasileiro de Comunicação em Enfermagem; 1992; Ribeirão Preto. Ribeirão Preto: Escola de Enfermagem de Ribeirão Preto/Universidade de São Paulo; 1992. p. 122-4.

6. Stefanelli MM. Comunicação com o paciente: teoria e ensino. 2a ed. São Paulo: Robe; 1993.

7. Matheus MCC, Colvero L de A, Ique CE, Dias DC. Passagem de plantão verbal e não verbal. Acta Paul Enferm. 1998;11(2): 77-82.

8. Pirolo SM. A equipe de enfermagem e o mito do trabalho em grupo [dissertação. São Paulo (SP): Escola de Enfermagem, Universidade de São Paulo; 1999.

9. Siqueira ILCP, Muto M. Apresentação e avaliação de um método de passagem de plantão em Unidade de Internação. In: Anais do $6^{\circ}$ Encontro de Enfermagem e Tecnologia; 1998 abr 5-8; São Paulo. São Paulo: ENFTEC; 1998. p. 404-9.

10. Silva RF da, Stacciarini JMR. Qualidade da comunicação do enfermeiro: passagem de plantão. In: Anais do $2^{\circ}$ Simpósio Brasileiro de Comunicação em Enfermagem; 1990; Ribeirão Preto. Ribeirão Preto: Escola de Enfermagem de Ribeirão Preto/Universidade de São Paulo; 1990. p. 271-86.

11. Oliveira C. Implantação e desenvolvimento do processo de enfermagem na Unidade de Internação. In: $1^{\circ}$ Ciclo de Debates da Enfermagem; 1988; São Paulo. São Paulo: ABEn-Seção SP; 1988. p. $54-8$. 
ANEXO

Plano de Passagem de Plantão

\begin{tabular}{|c|c|c|c|c|c|c|c|c|c|}
\hline Quarto & Paciente & Médico & $\mathrm{SO}$ & Exames & Exames & Resultados & Procedimento & Aguarda & Observações \\
\hline 01 & & & & & & & & & \\
\hline 02 & & & & & & & & & \\
\hline 03 & & & & & & & & & \\
\hline 04 & & & & & & & & & \\
\hline 05 & & & & & & & & & \\
\hline 06 & & & & & & & & & \\
\hline 07 & & & & & & & & & \\
\hline 08 & & & & & & & & & \\
\hline 09 & & & & & & & & & \\
\hline 10 & & & & & & & & & \\
\hline 11 & & & & & & & & & \\
\hline 12 & & & & & & & & & \\
\hline 14 & & & & & & & & & \\
\hline 15 & & & & & & & & & \\
\hline 16 & & & & & & & & & \\
\hline 17 & & & & & & & & & \\
\hline 21 & & & & & & & & & \\
\hline 22 & & & & & & & & & \\
\hline 23 & & & & & & & & & \\
\hline 24 & & & & & & & & & \\
\hline
\end{tabular}

